\title{
Influence of Microstructure on the Properties of Resistance Spot Welds ${ }^{1}$
}

\author{
M. L. Santella, S. S. Babu, B. W. Riemer, and Z. Feng
}

M. L. Santella

S. S. Babu

B. W. Riemer

Z. Feng
Oak Ridge National Laboratory, Oak Ridge, TN 37931, USA

Oak Ridge National Laboratory, Oak Ridge, TN 37931, USA

Oak Ridge National Laboratory, Oak Ridge, TN 37931, USA

Edison Welding Institute, Columbus, $\mathrm{OH} 43221$, USA

\footnotetext{
This manuscript was authored by a contractor of the U.S. Goversment under contract no. DE-AC05-96OR22464. Accordingly, the U.S. Government retains a nonexclusive, royalty-free license to publish or reproduce the published form of the contribution, or allow others to do so, for U.S. Government purposes.
}

\section{DMTREUTION OF THIS COCUMEAT O UMMTED}

1 This research was sponsored by the Division of Materials Sciences, U.S. Department of Energy, under contract DE-AC05-96OR22464 with Lockheed Martin Energy Research Corporation with Lockheed Martin Energy Research Corporation. 


\section{DISCLAIMER}

This report was prepared as an account of work sponsored by an agency of the United States Government. Neither the United States Government nor any agency thereof, nor any of their employees, makes any warranty, express or implied, or assumes any legal liability or responsibility for the accuracy, completeness, or usefulness of any information, apparatus, product, or process disclosed, or represents that its use would not infringe privately owned rights. Reference herein to any specific commercial product, process, or service by trade name, trademark, manufacturer, or otherwise does not necessarily constitute or imply its endorsement, recommendation, or favoring by the United States Government or any agency thereof. The views and opinions of authors expressed herein do not necessarily state or reflect those of the United States Government or any agency thereof. 


\section{DISCLAIMER}

Portions of this document may be illegible in electronic image products. Images are produced from the best available original document. 


\section{Introduction}

Resistance welding was invented over a century ago, and it has evolved into a simple, straightforward manufacturing process that is fast, easily automated, and easily maintained. These characteristics make resistance welding a preferred process in mass production manufacturing situations including those for automobile construction. Despite its desirable qualities, resistance welding can be difficult to control, which raises concerns about the quality of resistance spot welds. Uncertainties about quality are responsible for the practice of making more spot welds than are needed for maintaining structural integrity. For instance, various automobile components may be 'over-welded' by as much as $30 \%$. The significant cost associated with over-welding provides a considerable driving force for optimizing the process.

To make consistently good welds (using any process), two conditions must be met. First, an optimum set of welding parameters must be defined to produce the properties desired of the weld. Second, controls must be implemented to maintain process variables within the necessary ranges so that optimized welds can reproducibly be made.

Standard procedures for optimizing resistance spot welds rely on evaluation of some physical attributes of the welds. ${ }^{1}$ For instance, process variables are adjusted to produce a desired weld indentation depth or nugget size. For carbon steels, process variables such as welding current, welding time and squeeze pressure are selected based on material thickness rather than composition. Consequently, the same optimization procedure used for low strength plain carbon steels would also be applied to high strength steels. However, weldment properties depend on microstructure, and the welding parameters that produce optimized properties for one steel may not be optimized for a different one. This means that relying on physical attributes to specify resistance spot welding parameters is inherently unreliable.

The work presented here on microstructure development is part of a comprehensive effort to optimize resistance welding by more accurately describing and integrating the physics, metallurgy and mechanics of the process. The overall approach is outlined in Fig. 1. For

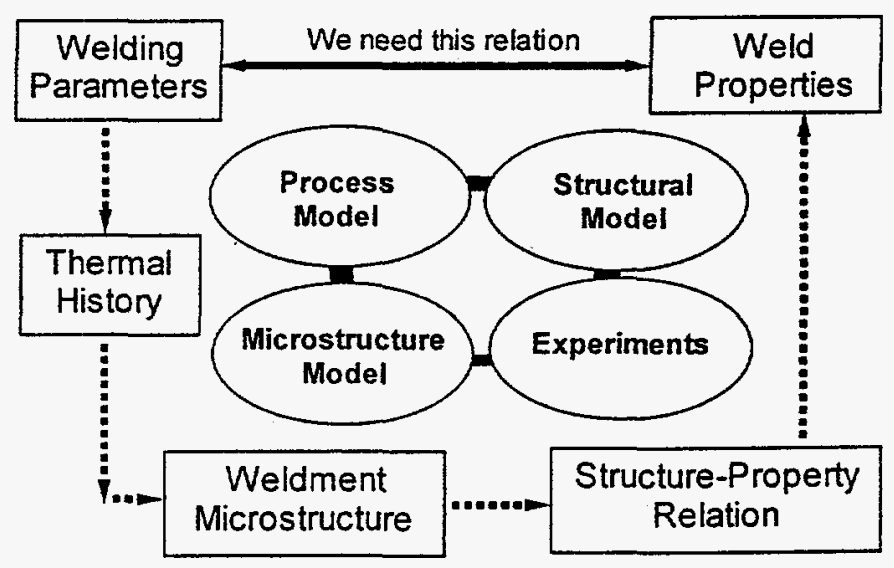

Fig. 1. Schematic illustration of integrated weld model.

any welding process and alloy a process model can be constructed to determine how the thermal history of the fusion zone and surrounding base material depends on welding parameters. Knowing the thermal history and the relevant metallurgical information about the alloy being welded, the microstructure throughout the entire weldment can be predicted. This step is embodied in the microstructure model. The microstructure gradient in the weldment will result in a mechanical property gradient that can be defined if the necessary microstructureproperty relationships are known or determined experimentally. Once the gradient of properties is 
established, then the response of the weldment to external - loading can be predicted. This can be done, for instance, by using finite element analysis to create a structural model of the entire welded component.

Microstructure Models: Microstructure models for resistance spot welds must be capable of describing the phase transformations during heating and cooling. In the past, there have been many efforts to model microstructure development in the fusion zones and heataffected-zones (HAZ) of welds. ${ }^{2-7}$ In general, these models describe the austenite formation and precipitate dissolution during heating and the austenite decomposition during cooling ${ }^{3,6}$ The model by Ion et. al. relates the carbon equivalence $\left(\mathrm{C}_{\mathrm{Eq}}\right)$ value and time to cool from $800{ }^{\circ} \mathrm{C}$ to $500{ }^{\circ} \mathrm{C}\left(\Delta t_{800-500}\right)$ to volume fractions of bainite, martensite and ferrite-pearlite phase mixtures (see Fig. 2). ${ }^{3}$ This model is widely used. However, its predictions of microstructure are not accurate at low cooling rates for low carbon steels. ${ }^{4}$

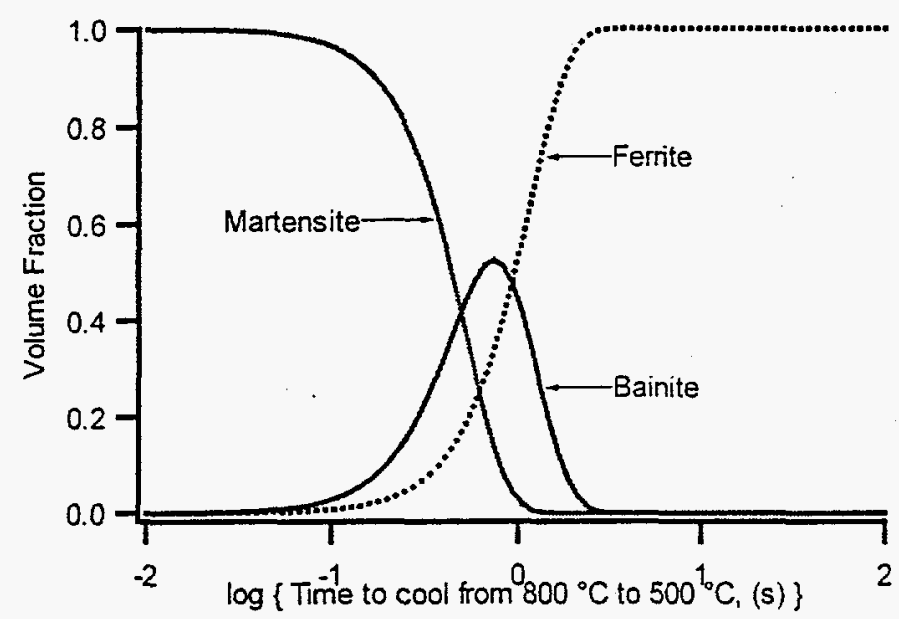

Fig. 2. Typical variation of phase fractions with time to cool from $800^{\circ} \mathrm{C}$ to $500{ }^{\circ} \mathrm{C}$ for a given steel composition [Fe - 0.048 C - 0.1 Si $-0.18 \mathrm{Mn}$ (wt. \%)], calculated using the expression given by Ion et $a l .^{3}$

Another model based on rate equations described by Watt et al. is generally valid for high carbon steels. ${ }^{5}$ This is because the rate equations were developed using high carbon steel time-temperature-transformation (TTT) diagram data. Also, Bhadeshia et al. developed a phenomenological model for sequential decomposition of austenite to various ferrite morphologies. ${ }^{6}$ The Bhadeshia model is applicable for a wide range of weld cooling rates and for low carbon steels. ${ }^{4}$ However, this model is incapable of describing simultaneous transformation of austenite to different ferrite phases. Recently, Jones and Bhadeshia developed a more refined model for describing the simultaneous formation of idiomorphic and allotriomorphic ferrite based on overall transformation kinetics equations. ${ }^{7}$ The possibility of extending this work to consider other ferrite morphologies and also reverse transformation appears feasible.

Our long-term objective is to incorporate microstructure modeling of the type developed by Jones and Bhadeshia into our effort. The work presented here, however, represents an effort to establish the feasibility of our overall approach, and to demonstrate the key role played by microstructure modeling. Consequently, for the sake of expediency, these results for microstructure development in resistance spot welds were obtained with the model of Ion et al. However, some of the transformation temperatures were calculated using ThermoCalc ${ }^{8}$ to estimate the austenite formation during heating. A more generalized approach based on alloy thermochemistry and phase transformation kinetics is still under development.

\section{Experimentation}

The alloy used for this study was an uncoated plain carbon steel (supplied by Inland Steel Co.). Its analyzed composition and designation is given in Table 1 . It was supplied as an 0.81 -mm-thick sheet.

Table 1. Chemical composition of DQSK steels (wt\%)

\begin{tabular}{lllllll}
\hline Alloy & $\mathrm{C}$ & $\mathrm{Si}$ & $\mathrm{Mn}$ & $\mathrm{Ti}$ & $\mathrm{Nb}$ & Bal. \\
\hline DQSK & 0.048 & 0.01 & 0.18 & 0.001 & 0.003 & $\mathrm{Fe}$ \\
\hline
\end{tabular}

The resistance spot welds were made with a benchmounted, single phase, direct energy machine. Its stacked core transformer was rated at $100 \mathrm{kVA}$. The machine was also fitted with a PC-based process control and data acquisition system. Male cap taper electrodes (ME25 CMW, T. J. Snow Co., Inc.) were used corresponding to RWMA Class 2, RWMA alloy no. 2.18200 (Wrought $\mathrm{Cu}-\mathrm{Cr}$ alloy). The truncated cone electrodes were dressed to a 5$\mathrm{mm}$-nominal face diameter. Conditioning of the electrodes and determination of welding parameters was done using industry guidelines for welding automotive sheet steels. ${ }^{1}$

The parameters finally used to make the spot welds were $2224 \mathrm{~N}(500 \mathrm{lb})$ welding force at a current of 7800 A for 12 cycles

Standard techniques were used for both optical and electron metallography.

All finite element analyses were done using ABAQUS software running on a stand-alone UNIX workstation. Microstructure modeling was done on a PC.

\section{Results and Discussions}

Weld Microstructure: The microstructures typical of those found in resistance spot welds of the DQSK steel are shown in Fig. 3. 


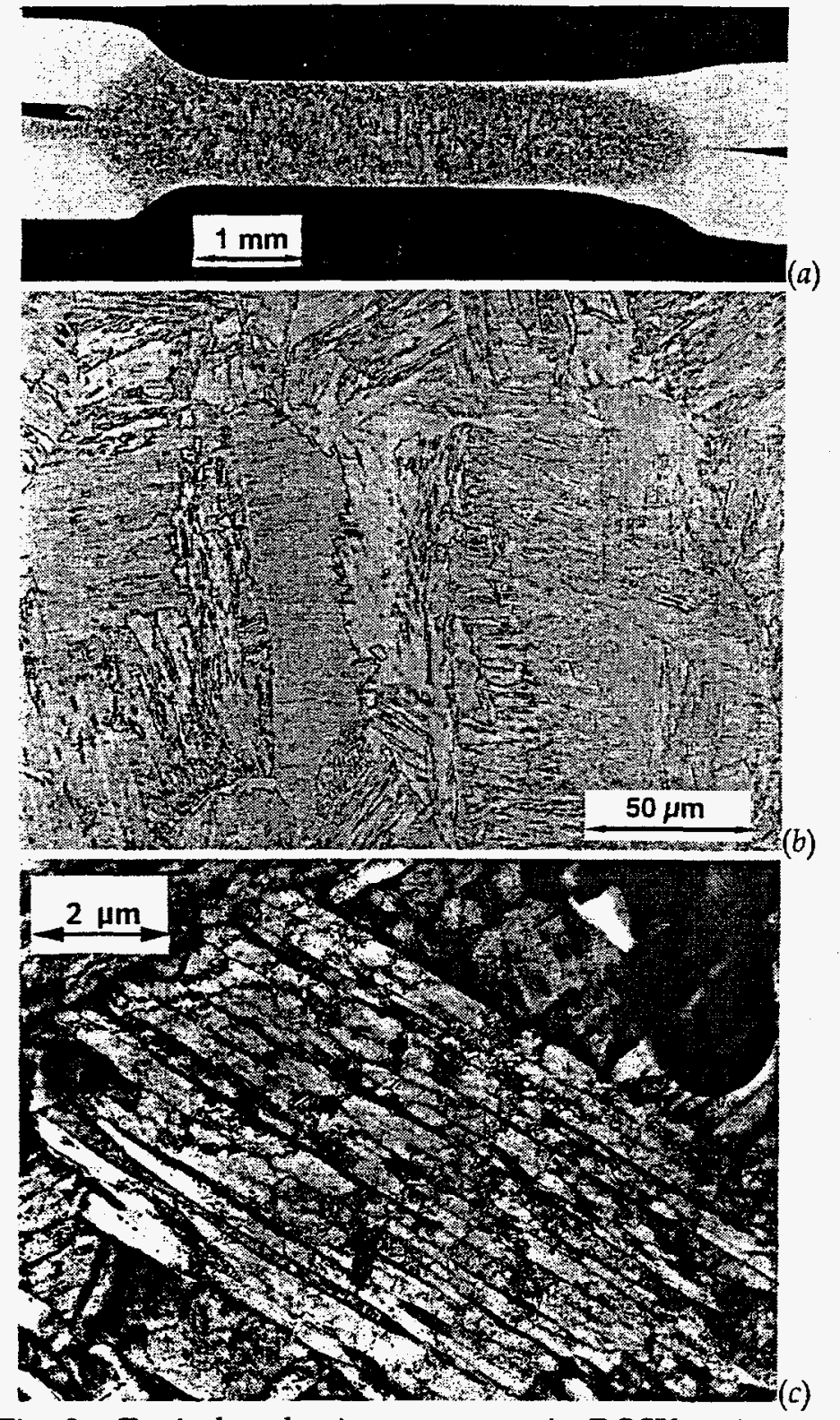

Fig. 3. Typical and microstructures in DQSK resistance spot welds: (a) Weld zone after 12 cycles; (b) Weld metal region exhibiting martensite and bainitic microstructures; and $(c)$ Transmission electron micrograph showing bainitic sheaves made up of ferrite sub-units. Other areas showed the presence of lath martensite.

Figure 3(a) shows the overall weld nugget appearance with fusion zone, and regions of fully austenitized, partially austenitized, tempered, and unaffected based metal. Optical microscopy at high magnification showed both martensitic and bainitic constituents in the weld nuggets. Transmission electron microscopy confirmed the presence of both martensite and bainite in the weld metal. The carbon content of DQSK steel $(0.048 \mathrm{wt} \%)$ is low, which means that the weld metal regions must have cooled at rapid rates to form bainitic and martensitic microstructures. Using the relation between microstructure and $\Delta t_{B 00-500}$ (see Fig. 2) the cooling rates are expected to be greater than $3000^{\circ} \mathrm{Cs}^{-1}$.

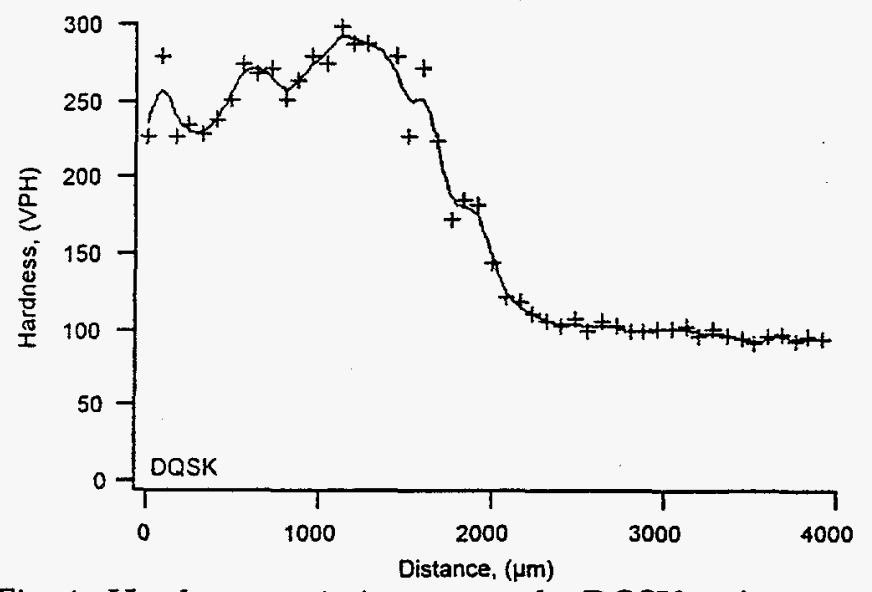

Fig. 4. Hardness variation across the DQSK resistance spot weld. Large hardness gradients are observed at the boundary between fusion zone and $\mathrm{HAZ}$.

The presence of martensite and bainite will lead to a very high hardness in the weld metal region and this was confirmed by experimental measurements, Fig. 4. A large hardness gradient was found in the HAZ. A smaller hardness gradient was also observed within the weld nugget, which could be related to variations in the cooling rates within this region. The hardness gradients across the weldment are expected to influence the final properties of these resistance spot welds. Preliminary cross-tension tests have supported this speculation. ${ }^{9}$

Microstructure Modeling: To be a useful tool, the integrated weld model (Fig. 1) must be capable of describing the effects of process variables on weldment properties. As previously discussed, a critical element of an integrated process model is a microstructure model. Existing process ${ }^{10-12}$ and microstructure models ${ }^{3}$ were used to evaluate the feasibility of our ability to construct an integrated model, and to establish its importance in determining structural integrity.

The microstructure modeling presented here is based on the thermal history of a resistance spot weld predicted with the relatively simple process model developed by Cho and Cho. ${ }^{10}$ For this thermal simulation, the welding parameters used were those established experimentally on DQSK with the electrodes removed at the end of 12 cycles. The thermal conditions at the end of 12 welding cycles are shown in Fig. 5(a). The left and bottom edges of Fig. 5(a) are symmetry axes so only one quadrant of the weld nugget (lower left corner) is shown. The thermal histories experienced by representative locations along the steel-steel interface corresponding to weld metal (Node 1), fully austenitized (Node 14), and partially austenitized (Node 270) regions are given in 
Fig.5(b). This thermal information was subsequently used - to calculate the fractions of ferrite, bainite, and martensite present at various locations throughout the weldment. Example results are given in Table 2. The calculations showed a large gradient in hardness and were generally in agreement with experimentally measured values.
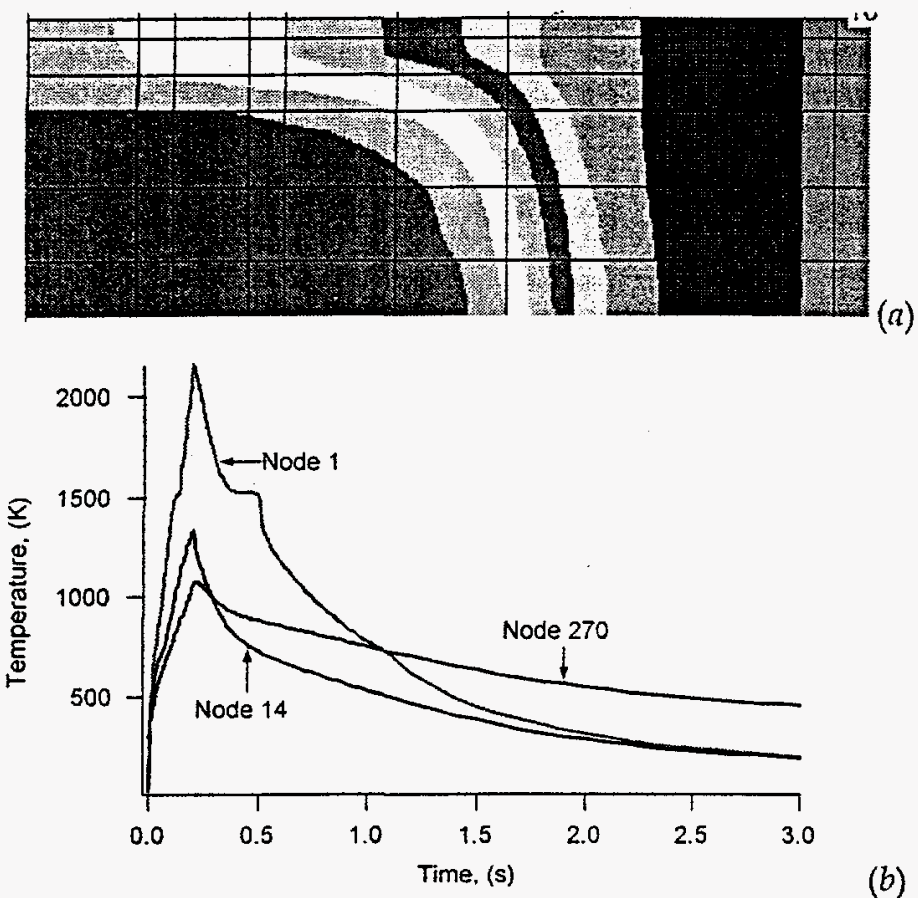

(b)

Fig. 5. (a) Calculated distribution of maximum temperature in the resistance weld for model of Cho and $\mathrm{Cho}^{10}$ (the image colors range from $1494^{\circ} \mathrm{C}$ to $200^{\circ} \mathrm{C}$ ). (b) Weld thermal cycles experienced at representative locations along the weld interface.

Table 2. Calculated microstructure and hardness for DQSK

\begin{tabular}{lllll}
\hline Region & Martensite & Bainite & Ferrite & VPH \\
\hline Node1 & 0.97 & 0.02 & 0.01 & 245 \\
Node14 & 0.99 & 0.01 & 0.00 & 258 \\
Node270 & 0.50 & 0.00 & 0.50 & 182 \\
\hline
\end{tabular}

Structure Property Relationship: Theoretically, the microstructure at various locations in the weld should be related to its local yielding behavior through stress-strain relations given by:

$$
\sigma=\sigma_{Y S}+K \varepsilon^{n},
$$

where $\sigma$ is the true stress, $\sigma_{\mathrm{Ys}}$ is the yield stress, $\varepsilon$ is the true strain, $K$ and $n$ are constants. However, there is no comprehensive structure-property correlation to estimate the above equation from the different constituent fractions of microstructure. Therefore, in this work, we estimated hardness using the published relation given in Ion et al. ${ }^{3}$ Example hardness values are also given in Table 2 . Subsequently, the hardness values were used to estimate yield strength values from the expression: ${ }^{13}$

$$
\sigma_{Y S}=\left(\frac{H}{3}\right)(0.1)^{m-2} ; m=2.15
$$

The effect of microstructure on $K$ and $n$ were ignored. It is noteworthy that the relation between microstructure and stress-strain relationship is crucial to describe the deformation strains during resistance welding. ${ }^{14}$

After the microstructure calculations and tensile property estimations, structural model calculations were performed to evaluate the response of a single resistance spot weld to an externally applied shear load. The test geometry used in the calculation is shown schematically in Fig. 7. To simplify the analysis, the weldment was arbitrarily assigned 4 individual property zones based on the thermal history information provided by process modeling (Fig. 5(a)). These 4 zones corresponded to weld metal, base metal, and two localized intermediate regions of HAZ. The properties of the HAZ regions were derived from those of Nodes $14 \& 270$ in Table 2 . The sensitivity of the calculations to property gradients was evaluated by additional calculations where uniform properties (those of the DQSK base metal) were assumed throughout the joint.

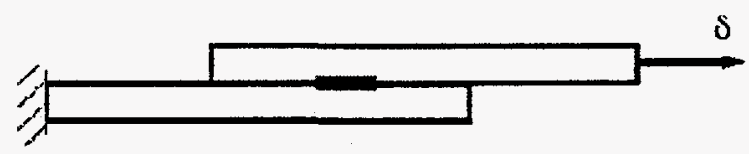

Fig. 7. Schematic of shear test geometry.
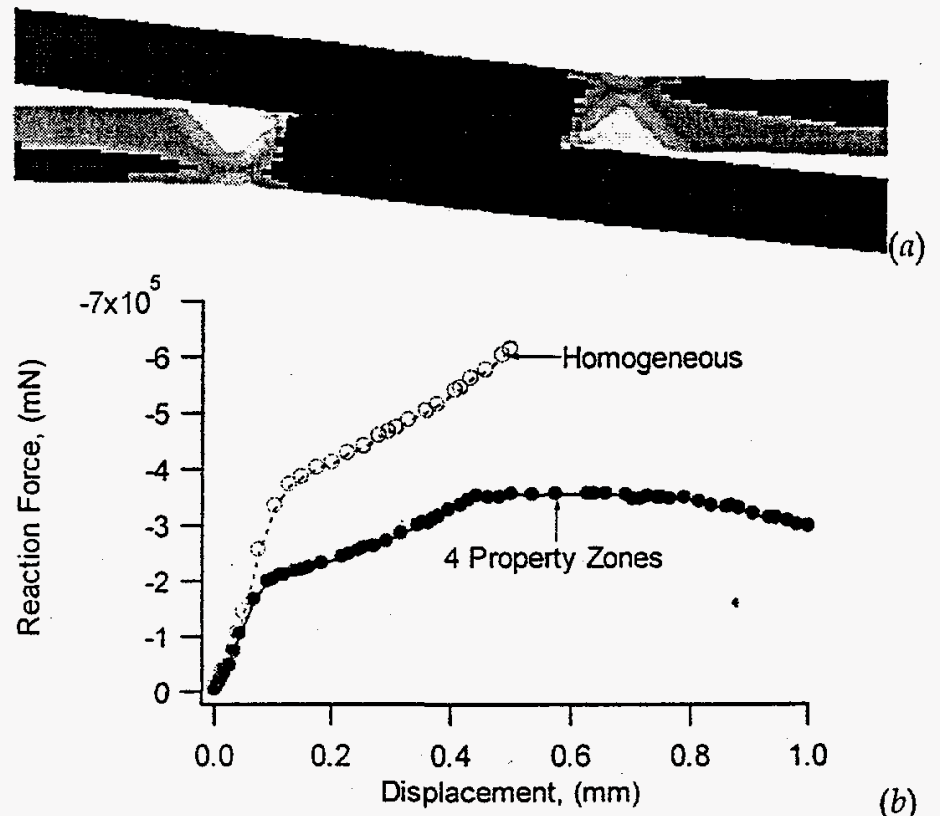

(b)

Fig. 8. Results of shear test simulation on resistance steel weld joint. (a) Strain distributions throughout the weld joint are shown by color gradients. Large strains are observed near the heat affected zone. (b) Loaddisplacement curves for weld joint with four property zones and for homogeneous properties. 
Predictions of the response of the weldments to - shear loading are shown in Fig. 8. The macroscopic deformation associated with shear loading is shown in Fig. $8(a)$. Shear loading produced a strain concentration in the $\mathrm{HAZ}$ regions of the weldments. The load-displacement behaviors for the two weldments are given in Fig. $8(b)$. The presence of the weld including property gradients reduced the overall load-carrying capacity for this geometry and loading condition by about $50 \%$. These results clearly indicate that gradients of microstructure and properties like those produced in resistance spot welds can have a significant effect on the mechanical behavior of a welded component.

It is anticipated that, when fully developed, the integrated model approach will provide a reliable means for systematically examining the influence that welding parameters and process conditions have on the mechanical behavior of welded components. It follows then that optimization of the resistance welding process should be possible based on the particular alloy and component being welded.

\section{Summary and Conclusions}

An integrated model approach was proposed for relating resistance welding parameters to weldment properties. A key element of the approach is microstructure modeling. It was demonstrated that existing process models and microstructure models can be used to determine the spatial distribution of microstructures and properties in resistance spot welds of a plain carbon steel. It was also shown by finite element analysis that the existence of microstructure gradients in the welds is expected to reduce their ability to support shear loads by about $50 \%$.

\section{Acknowledgments}

This research was sponsored by the Division of Materials Sciences, U.S. Department of Energy, under contract DEAC05-96OR22464 with Lockheed Martin Energy Research Corporation. The authors wish to thank Dr. J. W. Cohron, Dr. J. A. Horton and Mark W. Richey for allowing us to use unpublished research and Alan F. Frederick for technical assistance. The authors also thank Dennis Urban and Warren Peterson of Inland Steel Co. for their interest and support.

\section{References}

1. Recommended Practices for Test Methods for Evaluating the Resistance Spot Welding Behavior of Automotive Sheet Steels, ANSI/AWS/SAE D8.9-97, American Welding Society, Miami, FL, Final draft.
2. K. E. Easterling, Mathematical Modeling of Weld Phenomena, H. Cerjack and K. E. Easterling Eds, Institute of Materials, London, 1993, pp. 183-200.

3. J. C. Ion, K. E. Easterling, and M. F. Ashby, Acta. Metall., 32, 1949-1962 (1984).

4. E. A. Metzbower, G. Spanos, R. W. Fonda, and R.A. Vandermeer, Sci. Tech. Weld. Joining, 2, 27-32 (1997).

5. D. F. Watt, L. Coon, M. Bibby, J. Goldak, and C. Henwood, Actn. Metall.,36, 3029-3035, (1988).

6. H. K. D. H. Bhadeshia and L. -E. Svensson, Mathematical Modeling of Weld Phenomena, $\mathrm{H}$. Cerjack and K. E. Easterling Eds, Institute of Materials, London, 1993, pp.109-180.

7. S. J. Jones and H. K. D. H. Bhadeshia, Acta Metall., 45, 2911-2920 (1997).

8. B. Sundman, B. Jansson, and J.-O. Andersson, Calphad, 9, 153-190 (1985).

9. M. W. Richey et al. Unpublished Research, Lockheed Martin Energy Systems, Oak Ridge, 1998.

10. H. S. Cho and Y. J. Cho, Welding Journal, 68, 236s-244s, (1989).

11. C. L. Tsai, W. L. Dai, D. W. Dickinson, and J. C. Papritan, Welding Journal, 70, 339s-351s (1991)

12. H. A. Nied, Welding Journal, 63, 123s-132s, (1984).

13. J. R. Cahoon, W. H. Broughton, and A. R. Kutzak, Met. Trans., 2, 1979-1983 (1971).

14. Z. Feng, et. al., This conference.
This manuscript was authored by a contractor of the U.S. Government under contract no. DE-AC05-96OR22464. Accordingly, the U.S. Government retains a nonexclusive, royalty-free license to publish or reproduce the published form of the contribution, or allow others to do so, for U.S. Government purposes. 